\title{
A TOMADA DE DECISÃO NA ADMINISTRAÇÃO DA UNIDADE DE PRODUÇÃO AGRÍCOLA FAMILIAR: UM ESTUDO DE CASO
}

ADILSON R. PAZ STAMBERG

INSTITUTO FEDERAL FARROUPILHA - CÂMPUS SÃO BORJA

BRASIL

"No le temas al fracaso, que no te hará más débil, sino más fuerte".

Abraham Lincoln. 


\section{RESUMEN}

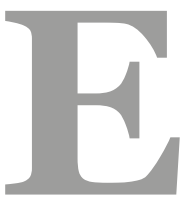

ste trabajo se centra en la comprensión de la racionalidad de la gestión de los recursos disponibles en la unidad de producción agrícola (UPA), la identificación de sus características técnicas y socioeconómicas con el fin de hacer un diagnóstico para subsidiar el gerente rural en la toma de decisiones en la producción estratégica de la organización rural. Este estudio de caso fue parte del proyecto de extensión empresarial rural, desarrollado en la comunidad de Nhu-Porã, São Borja / RS / Brasil, priorizando como objeto de estudio una unidad de producción familiar, siendo realizado en el período de octubre a noviembre 2014. Se realizó una encuesta de datos cualitativos y cuantitativos, como los recursos naturales, la superficie agrícola utilizada, manada, mejoras, maquinaria y equipo, la disponibilidad de mano de obra y las producciones de los diferentes subsistemas de cultivo, cría y procesamiento. Estos datos fueron organizados en una hoja de cálculo, la cual pertmitó identificar lo sistema de producción adoptado y sus características técnicas y socioeconómicas. En la evaluación económica, teniendo en cuenta los indicadores económicos globales obtenidos, se puede decir que la UPA se encuentra en una situación cómoda, cuya renta agrícola global puede superar el nivel de reproducción social (NRS), estipulado en este estudio en $\mathrm{R} \$$ 9,100.00. Como propuesta de la intervención técnica y de gestión, a partir de este diagnóstico, propose estratégicamente intensificar la producción de leche em detrimiento de la producción de soja, hasta su alta contribuición en relación con el valor añadido por unidad de área.

Palabras clave: gestión rural, planificación, unidad de producción.

\section{RESUMO}

Este trabalho aborda compreender a racionalidade da gestão dos recursos disponíveis na unidade de produção agrícola (UPA), identificando suas características técnicas e socioeconômicas, a fim de elaborar um diagnóstico para subsidiar o gestor rural na tomada de decisão estratégica de organização da produção. Este estudo de caso fez parte do projeto de extensão em empreendedorismo rural desenvolvido na comunidade de Nhu-Porã, município de São Borja / RS / Brasil, priorizando como objeto de estudo uma unidade de produção familiar, sendo realizado no período de outubro a novembro de 2014. Foi feito levantamento de dados qualitativos e quantitativos, como: recursos naturais, superfície agrícola útil, rebanho, instalações, máquinas e equipamentos, disponibilidade de mão-de-obra e das produções dos diferentes subsistemas de cultivo, 
criação e processamento. Estes dados foram sistematizados em uma planilha eletrônica, a qual permitiu identificar o sistema de produção adotado e suas características técnica e socioeconômica. Assim, considerando os indicadores econômicos globais obtidos, podese afirmar que a UPA encontra-se numa situação de capitalização, cuja renda agrícola global consegue superar o nível de reprodução social (NRS), estipulado neste estudo em $\mathrm{R}$ \$ 9.100,00. Como proposta de intervenção técnica e gerencial, a partir do diagnóstico, propôs-se estrategicamente intensificar a atividade leiteira em detrimento da produção de soja, visto sua alta contribuição em relação ao valor agregado por unidade de área.

Palavras-chave: gestão rural, planejamento, unidade de produção.

\begin{abstract}
This paper focuses on understanding the rationality of management of available resources in agricultural production unit (UPA), identifying their technical and socioeconomic characteristics in order to make a diagnosis to subsidize the rural manager in decision making in the organization's strategic production. This case study was part of the extension project in rural entrepreneurship, developed in the community of Nhu-Pora, São Borja / RS / Brazil, prioritizing as object of study a family production unit, being held in the period from october to november 2014. A survey was done of qualitative and quantitative data, such as natural resources, utilized agricultural area, herd, improvements, machinery and equipment, availability of labor, work and productions of different subsystems of cultivation, breeding and processing. These data were organized in a spreadsheet, which identified the adopted production system and its technical and socioeconomic characteristics. In economic evaluation, considering the global economic indicators obtained, it can be said that the UPA is in a comfortable situation, the overall farm income can overcome the level of social reproduction (NRS), stipulated in this study in $\mathrm{R} \$$ 9,100.00. As proposed technical and managerial intervention, from this diagnosis, proposed to strategically enhance milk production at the expense of soybean production, as its high contribution in relation to the value added per unit area.
\end{abstract}

Keywords: rural management, planning, production unit. 


\section{INTRODUÇÃO}

No contexto brasileiro, as grandes transformações vivenciadas nas últimas décadas do século XX tiveram influências significativas no espaço rural, especialmente os negócios agrícolas que, em grande parte, são frutos da reestruturação produtiva provocada pelo que se denominou de processo de modernização da base técnica dos sistemas de produção praticados na agricultura, a qual passou de um modelo de produção de subsistência da família para uma produção que atendesse ao mercado, perfeitamente adaptado aos requerimentos da indústria, a montante e a jusante ${ }^{1}$, e cujo objetivo era "modernizar" tecnologicamente a estrutura produtiva praticada nas unidades de produção agrícolas (UPAs).

Esse processo de modernização associado à complexidade dos fatores ambientais e socioeconômicos teve forte impacto no contexto rural, imprimindo características bastante diferenciadas às UPAs, configurando um cenário extremamente complexo e heterogêneo, fruto de um longo processo de diferenciação social e de várias possibilidades de combinações entre os fatores de produção, contextos regionais e formas sociais de organização da produção. Isso significa, portanto, que os diferentes tipos de unidade de produção são portadores de problemas, potencialidades e necessidades peculiares e agem com racionalidades específicas, estabelecendo estratégias próprias de sobrevivência e de produção, de modo a adaptarem-se ao meio nos quais estão inseridos.

Neste contexto, segundo Miguel (2010) considera-se que as UPAs são formatadas pela família-sistema de produção, que organizam suas atividades produtivas a partir das condições naturais e materiais, bem como de seu saber cultural, étnico e social. Assim, a compreensão da estrutura e do funcionamento da UPA e das particularidades que caracterizam os agentes diretamente envolvidos nesse processo é condição fundamental e indispensável para definição e realização de ações de gestão e planejamento nas unidades de produção. No entanto, essa definição está fortemente vinculada aos objetivos da família referentes tanto à atividade econômica desenvolvida quanto à sua inserção na sociedade. Assim, a elaboração de um diagnóstico técnico e socioeconômico da UPA constitui uma excepcional ferramenta de controle e gerenciamento das atividades produtivas, contribuindo na geração de importantes informações para subsidiar as tomadas de decisões estratégicas pelos produtores rurais.

Portanto, estudos sobre a organização da produção agrícola são de grande importância na administração rural, uma vez que refletem o nível tecnológico e a eficiência com que as operações são desenvolvidas na UPA. Assim, para que os produtores continuem a produzir é preciso que recebam uma remuneração pelos fatores de produção investidos por eles na atividade. E,

\footnotetext{
${ }^{1}$ Termos empregados para criar analogia entre um rio, seus afluentes e uma cadeia de suprimentos; "a montante" significa o trecho entre a nascente de um rio e um ponto qualquer do mesmo; "a jusante" significa trecho entre um ponto qualquer de um rio e a sua foz.
} 
para administrar com eficiência e eficácia uma unidade de produção, é imprescindível, dentre outras variáveis, o domínio da tecnologia e do conhecimento dos resultados dos gastos com os insumos e serviços em cada fase produtiva da lavoura, pecuária ou no processamento da matéria-prima destas, que tem no custo de produção um indicador importante nas escolhas do gestor rural. Esse processo de tomada de decisão reflete no seu custo total, que, por sua vez, impacta os resultados ótimos da atividade agrícola.

Percebendo que a UPA faz parte de um sistema complexo, dinâmico e em constante mudança, principalmente no que se refere a seus fatores de produção, motivou-se a realização deste trabalho no sentido de contribuir com informações que possam promover ações para a gestão e planejamento da UPA objeto de estudo. Contudo, buscou-se responder a seguinte questão básica: o diagnóstico técnico e socioeconômico do sistema de produção contribui para a tomada de decisão e promoção de estratégias de gestão rural?

Buscando resposta a esta questão, o trabalho compreende o estudo do funcionamento e a organização da produção da UPA familiar, cujo diagnóstico se constitui como um importante referencial para a gestão estratégica dos negócios agrícolas, bem como na tomada de decisões e planejamento da organização da produção, baseada na avaliação crítica do sistema produtivo desenvolvido, tendo como parâmetros a sua capacidade de gerar riqueza e de se reproduzir socialmente.

A capacidade de geração de riqueza é avaliada pelo valor agregado que a unidade de produção gera ao produzir bens e serviços postos à disposição da sociedade. A capacidade de reprodução social das organizações rurais familiares, por sua vez, pode ser mensurada pelo montante da riqueza produzida anualmente de que elas conseguem se apropriar a título de renda agrícola.

Além da introdução e das considerações finais, o trabalho aborda alguns elementos teóricos fundamentais para o estudo da UPA baseado na abordagem sistêmica da administração rural. Para tanto, são definidos diversos conceitos, bem como os elementos fundamentais para a caracterização técnica, social e econômica da unidade de produção, tendo como centro de observação a família-sistema de produção, bem como descreve os procedimentos metodológicos utilizados e, em seguida, apresenta e discute os principais resultados alcançados pelo sistema de produção desenvolvido pela UPA.

\section{FUNDAMENTAÇÃO TEÓRICA}

\section{ADMINISTRAÇÃO DE ORGANIZAÇÕES RURAIS}

A administração faz parte da história da humanidade, pois onde se encontram pessoas visando o alcance de objetivos, torna-se necessária a ação dos procedimentos administrativos. 
Para Souza et al (1998) a administração é uma ciência e também uma arte. Ciência porque possui um referencial teórico próprio, passível de ser tratado pelo método científico. $\mathrm{E}$ arte porque inclui, na resolução dos problemas que surgem na condução das organizações, habilidade, sensibilidade e intuição.

Segundo Lima et al. (2005) o desenvolvimento teórico e prático da administração rural toma por base duas abordagens. De um lado, enquanto ramo da economia rural e, de outro, sob a égide do arcabouço teórico da ciência administrativa.

A primeira abordagem é representada basicamente pela obra de Hoffmann et al.(1987), onde a administração rural é definida como um ramo da economia rural que estuda a organização e administração de uma empresa agrícola, visando o uso mais eficiente dos recursos para obter resultados mais compensadores e contínuos". Essa abordagem permanece vinculada à perspectiva inicial, restringindo a prática e os problemas de estudos administrativos a uma análise estritamente econômica. Observa-se até mesmo, pouca preocupação com o processo que torna possível o uso mais eficiente dos recursos, ou seja, com a ação administrativa propriamente dita. Trata-se, contudo, de uma abordagem extremamente importante e indispensável, porém insuficiente no tratamento das diferentes dimensões da problemática administrativa nas organizações rurais.

A segunda abordagem encontra-se referenciada na obra de Souza et al. (1989) a qual define administração rural como um ramo da ciência administrativa que se preocupa com a análise dos aspectos inerentes a empresa rural e suas inter-relações com o meio ambiente. É um enfoque que aplica, às empresas rurais, o conceito administrativo concebido nas empresas industriais e comerciais. Com isso, buscam contemplar os diferentes elementos do processo administrativo, todas as áreas e os níveis hierárquicos da empresa e o seu relacionamento com o meio ambiente. Esse enfoque representa, também, um ponto de referência sumamente importante para os estudos e a prática em administração rural, principalmente, porque supera a perspectiva economicista e setorial da atividade administrativa nas empresas rurais, ao abordá-la de forma mais completa. É, no entanto, uma referência mais recente que ainda carece de aprofundamento, especialmente no que concerne à sua aplicabilidade em face das particularidades das organizações rurais e da diferenciação socioeconômica existente entre elas (LIMA, 2005, p. 22-23).

Podemos definir, de uma maneira geral, a administração rural como a área de estudo que leva em consideração a operação e organização de uma empresa rural, tendo em vista a utilização eficiente dos recursos disponíveis, para obtenção de fluxos contínuos de resultados satisfatórios. Para Andrade (1985) a administração rural como ramo da ciência administrativa possibilita o acesso às teorias administrativas, ou seja, desde a abordagem clássica de Tayor e Fayol à moderna teoria do desenvolvimento organizacional. Assim, as áreas empresariais 
(produção, finanças, comercialização, marketing, materiais e recursos humanos) e as funções administrativas (planejamento, organização, direção e controle) serão igualmente consideradas e analisadas como um todo sistêmico no processo da administração rural, visando sempre o alcance de lucratividade e competitividade.

Entretanto, esse processo administrativo será mais bem exercido, quando variáveis peculiares internas e externas forem bem conhecidas por parte da administração rural, pois no desenvolvimento da produção agrícola, esta apresenta características específicas que devem ser consideradas, tais como: a) dependência do clima; b) mercado consumidor para os produtos; c) condições e características dos produtos (perecibilidade / tamanho / oferta no mercado, etc.); d) área disponível na propriedade; e) tecnologia disponível na propriedade; f) mão de obra capacitada e disponível; g) entre outros.

Neste sentido, conforme Brossier (1990) a tomada de decisão e os modos de gestão nas unidades de produção agrícolas constitui, a partir da teoria da microeconomia da firma, o primeiro esforço de elaboração de um modelo que foca o comportamento dos produtores (o que, quanto, por que e para quem produzir). O objetivo principal não é compreender o funcionamento das unidades de produção e sim conhecer como funciona uma economia global que a age sobre pequenas unidades de produção. Com esse modelo é possível determinar quais são os produtos que deverão ser produzidos (o que), em que nível (quanto) e com quais fatores de produção (como). Assim, a decisão de produzir será tomada quando os gastos de uma unidade de produção suplementar são inferiores às receitas, ou seja, quando for possível obter lucro com a atividade agrícola, ou seja, quando a produção agrícola reproduzir a mão-de-obra dos membros da família e os demais fatores de produção.

\section{O ENFOQUE SISTÊMICO NA GESTÃO DA UNIDADE DE PRODUÇÃO AGRÍCOLA}

Segundo Lima et al. (2005) a produção de conhecimento e a prática em administração rural caracterizam-se fundamentalmente pelo enfoque sistêmico, sofrendo em consequência, influência do meio onde a unidade de produção está inserida.

A abordagem sistêmica oriunda da Teoria Geral dos Sistemas (TGS), formulada por Ludwig Von Bertalanfy na metade da década de 1950, surgiu como uma nova forma de pensamento em diversos campos das ciências sociais. Atualmente, ao se buscar compreender a realidade das organizações rurais e as cadeias produtivas, é necessário analisá-las por meio do enfoque sistêmico, pois o negócio agrícola tem a mesma dinâmica dos demais setores da economia e, para ser bem gerenciado, é necessário um perfeito conhecimento do que ocorre dentro da unidade de produção e do ambiente no qual ela está inserida (ANDRADE, 2001).

Um sistema representa os elementos que se interagem e se inter-relacionam no ambiente, sendo possível definir sistema como "um todo complexo e organizado, um conjunto ou combinação de coisas ou partes que formam um todo complexo e unitário” (MEGGINSON, 
1998, p. 66). Neste sentido, a caracterização da administração rural e da unidade de produção em sua essência assume fundamental importância para o entendimento das suas relações. Assim, o enfoque sistêmico oferece ao administrador uma visão geral integrada das organizações e do processo administrativo, além de ser uma ferramenta importante para organizar os sistemas que produzem resultados.

Portanto, segundo Miguel (2010) administrar a UPA como um sistema é, antes de tudo, estudá-la em seu conjunto, para depois analisá-la em suas partes. Os elementos que constituem uma UPA, vista como sistema dinâmico, são os insumos, os produtos, serviços e subprodutos consumidos, estocados, transformados ou vendidos; os meios de produção representados pelas glebas de terra, animais, instalações, máquinas e equipamentos, a força de trabalho física e intelectual e pelos recursos financeiros. Assim, o estudo da administração rural deve ser conduzido pela análise das inter-relações existentes sobre o que ocorre dentro dos limites da unidade de produção e o que ocorre entre os seus fornecedores e clientes.

Neste sentido, a abordagem sistêmica constitui uma nova concepção científica fundamental para a compreensão e a análise da estrutura e funcionamento da UPA. Segundo Basso et al. (2003) trata-se de uma forma de abordar as condições e modalidades de produção agrícola nos mais diversos níveis, contemplando toda a sua complexidade e diversidade, permitindo entender os mecanismos de reprodução socioeconômica das UPAs, bem como, um instrumento de análise da evolução histórica e das modificações que se processam no ambiente agro-socioeconômico no qual as unidades de produção estejam inserido.

Além da ênfase na interação das partes constituintes, busca ressaltar a organização rural e a noção de finalidade, baseada no princípio de que todo e qualquer objeto pode ser analisado e compreendido como um sistema. Para Mazoyer e Roudart (2001) as diferentes formas agrícolas observáveis levam ao entendimento das questões que envolvem o estudo em termos de sistema, em que analisar e explicitar um objeto complexo é, em primeiro lugar,

[...] delimitá-lo, isto é, traçar uma fronteira, virtual, entre esse objeto e o resto do mundo, e é considerá-lo como um todo, composto de subsistemas hierarquizados e interdependentes. Por exemplo, a anatomia de um ser vivo superior é concebida como um sistema (ou organismo) composto de subsistemas (ou aparelhos): ósseo, muscular, circulatório, respiratório, decompondo-se cada um desses em órgãos, cada órgão em tecidos, cada tecido em células, etc.

Analisar e conceber um objeto complexo e animado em termos de sistema é considerar também o seu funcionamento como uma combinação de funções independentes e complementares, que asseguram a circulação interna e as trocas com o exterior: de matéria, de energia e, tratando-se de um objeto econômico, de valor. Por exemplo, o funcionamento de um ser vivo superior é concebido como um conjunto de funções: digestiva, circulatória, respiratória, reprodutora, etc. , que concorrem para renovação do organismo. Assim, analisar e conceber em termos 
de sistema agrário a agricultura praticada num momento e espaço determinados consiste em decompô-la em dois subsistemas principais, o ecossistema cultivado e o ecossistema social produtivo, em estudar a organização e o funcionamento de cada um desses subsistemas, em estudar as suas inter-relações (MAZOYER \& ROUDART, 2001, p. 40.).

Segundo Lima et al. (2005), na perspectiva da compreensão da realidade de desenvolvimento da UPA, a abordagem sistêmica tem se tornado cada vez mais necessária, devido à crescente complexidade dos sistemas de produção organizados e desenvolvidos pelo produtor e da evidente emergência dos conceitos de sustentabilidade, em suas várias dimensões, estabelecendo uma nova relação entre a ciência e a realidade. Desta forma, esta abordagem seguramente pode ser considerada como pragmática, pois serve de subsídio teórico e metodológico ao processo de gestão e planejamento, fornecendo instrumentos importantes na identificação das condicionantes históricas, sociais, econômicas e ecológicas que caracterizam a unidade de produção familiar.

Com o intuito de organizar e hierarquizar, no tempo e no espaço, a interação dinâmica entre os elementos que compõe a realidade rural, torna-se relevante explicitar alguns conceitos básicos amplamente utilizados para a caracterização da UPA segundo a abordagem sistêmica. Para Miguel (2010), a UPA pode ser definido como sendo o "objeto" resultante da interação do sistema social com o sistema natural. Ou seja, pode ser concebido como um sistema dinâmico de um conjunto de elementos em interação (sistemas de cultivo e/ou criação e/ ou transformação), influenciado pelos objetivos do produtor rural e de sua família (sistema social), aberto e em interação com o meio externo (econômico, físico e humano). A partir desta definição de unidade de produção, pode-se delimitar, de maneira clara e precisa o objeto de estudo e de análise, bem como sua inserção e articulação com o ambiente externo.

O sistema de produção pode ser definido, segundo Dufumier (2007), considerando a escala de exploração da UPA, como uma combinação (no tempo e no espaço) dos fatores de produção disponíveis na propriedade rural, como por exemplo, a força de trabalho, o conhecimento técnico, a superfície agrícola útil, as benfeitorias, máquinas e equipamentos agrícolas, o capital, entre outros, visando à produção de vegetais e animais. Tem-se, também, concebido como uma combinação mais ou menos coerente de diversos subsistemas produtivos, tais como:

a) o sistema de cultivo pode ser definido a partir da forma como uma determinada parcela ou gleba de terra é cultivada ao longo dos períodos agrícolas, combinando os fatores de produção e modalidades técnicas tratadas de maneira idêntica ou homogênea na condução de uma ou mais cultura vegetal numa mesma UPA, compreendendo, a natureza das culturas e sua ordem de sucessão (a evolução da população vegetal, rotação no tempo, etc); os itinerários técnicos praticados (sucessão lógica e ordenada de operações técnicas elementares); o nível de produção obtido e os efeitos do sistema sobre a reprodução da fertilidade.

b) o sistema de criação corresponde à forma como são conduzidas as produções animais, 
caracterizando-se por um conjunto de atividades inter-relacionadas coordenadas pelo produtor rural, combinando numa mesma UPA, recursos disponíveis e itinerários técnicos para intervenção no manejo de seleção, de reprodução, de alimentação, de sanidade, entre outros, com a finalidade de produzir produtos ou subprodutos animais.

c) o sistema de processamento são os produtos agrícolas transformados no estabelecimento rural (agroindústria).

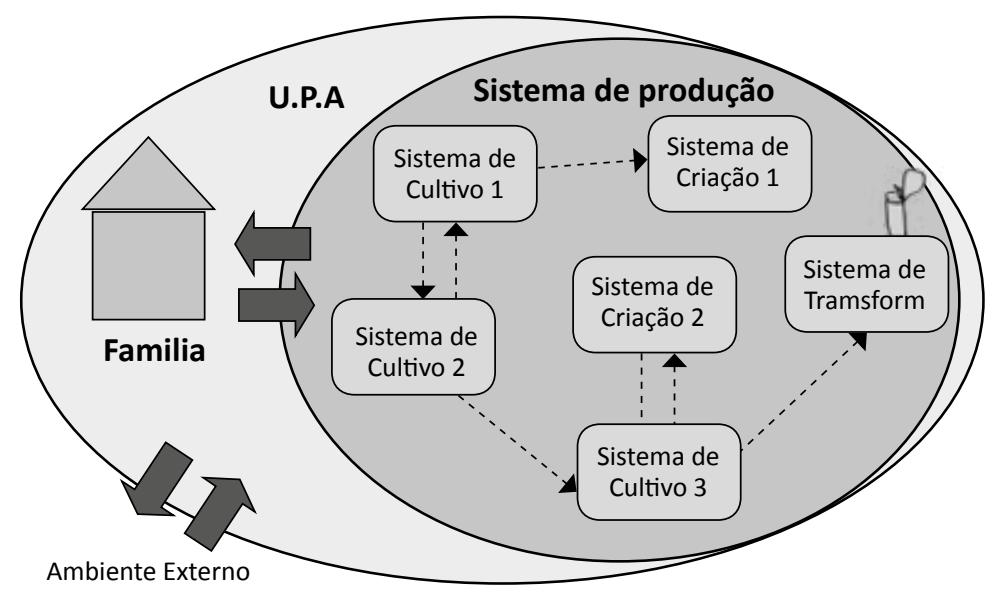

Representação da Unidade de Produção Agrícola e do Sistema de Produção segundo a abordagem sistêmica. Adaptado de MIGUEL, Lovois de Andrade, 2010.

Para Miguel (2010) a compreensão da estrutura e funcionamento de uma UPA, bem como de sua evolução deve considerar simultaneamente os projetos do grupo familiar e o modo de produção como componentes indissociáveis de seu funcionamento. Isso exige um profundo conhecimento da disponibilidade de fatores de produção (terra, trabalho e capital), que normalmente é realizada com base em um inventário quantitativo.

Para o mesmo autor, a extraordinária complexidade que envolve o processo de produção em uma UPA exige uma aproximação progressiva. Primeiro busca-se delimitar e descrever os diferentes sistemas de criação e de cultivo, colocando em evidência suas particularidades e eventuais relações de troca e reciprocidade. Em um segundo momento, em uma escala de abrangência superior, busca-se restituir o sistema de produção colocado em prática na unidade de produção a partir de seu contexto histórico. Pode-se, pois, de maneira sucinta e objetiva, afirmar que o estudo e a compreensão da estrutura e do funcionamento de UPAs estão fundamentados em quatro postulados: a) a UPA é um sistema; b) as decisões dos agentes (agricultor/família ou externos) é que fazem evoluir a UPA de um estado a outro; c) o agricultor/família tem influência determinante sobre a estrutura e o funcionamento; e d) o conhecimento das possibilidades de evolução da UPA demanda uma análise de sua história. 


\section{METODOLOGIA}

O trabalho foi desenvolvido em uma UPA familiar no município de São Borja/RS/Brasil, tendo como base o ano agrícola de 2013/2014. Para caracterização técnica e socioeconômica do sistema de produção fez-se levantamentos quantitativos e qualitativos referentes à unidade de produção, como: terras próprias, arrendadas e/ou em parceria; superfície agrícola útil (SAU); levantamento do rebanho, das instalações, máquinas e equipamentos; da disponibilidade de mão-de-obra familiar e das produções dos diferentes sistemas de cultivo e criações, entre outros aspectos relevantes, retratando o sistema de produção praticado pela unidade familiar.

Os dados coletados foram sistematizados em uma planilha eletrônica, construindo-se a tipologia da UPA, sendo que o critério básico está associado àqueles fatores que diferenciam o processo de desenvolvimento das unidades de produção, considerando: (a) combinação das produções e; (b) disponibilidade dos meios de produção, particularmente, da mão-de-obra, do tipo de força de tração (animal ou mecanizada) e da superfície agrícola útil (SAU).

Para determinação dos resultados econômicos globais da UPA, necessário para que se possa realizar a avaliação da capacidade de reprodução socioeconômica, utilizou-se a metodologia citada por Lima et al. (2005), baseado em dois fatores principais:

(a) análise de medidas e critérios de desempenho econômico da propriedade rural através de cálculos da produção bruta; custo intermediário das produções; depreciação das instalações, máquinas e equipamentos; valor agregado; distribuição do valor agregado e renda agrícola.

(b) para a análise de reprodução e desempenho econômico e financeiro da unidade familiar, utilizou-se como parâmetro o nível de reprodução social (NRS), o qual se baseia na renda agrícola mínima necessária para reproduzir os meios de produção da unidade produtiva e remunerar o agricultor e sua família ao longo do tempo.

Utilizaram-se como base teórica e metodológica os conceitos e procedimentos de diagnóstico e aconselhamento técnico e gerencial. O diagnóstico consiste no processo de análise e avaliação da coerência e eficácia da forma como o produtor vem utilizando seus recursos em relação aos seus objetivos fundamentais e estratégicos de reprodução social, tendo em vista as condições objetivas sob as quais ele atua no espaço e no tempo. Já o aconselhamento técnico-gerencial aos produtores rurais, é uma proposta de intervenção no processo de desenvolvimento da unidade de produção, no sentido de confirmar ou transformar a tendência verificada (LIMA, 2005).

O procedimento metodológico empregado baseou-se em levantamento de informações primárias, por meio de pesquisa de campo, mediante entrevistas com produtores, além de dados secundários através de pesquisas bibliográficas.

A partir dos dados obtidos junto a UPA foi auferido o resultado econômico proporcionado pelo sistema de produção. Tal resultado foi analisado globalmente e, também, segundo a contribuição que cada subsistema (de cultura, de criação ou de processamento) proporciona ao 
resultado global. A análise do resultado econômico global do sistema de produção destina-se avaliar o potencial de geração de riquezas para a sociedade de um tipo de sistema de produção, medido pelo valor agregado (VA), e da capacidade de reprodução social ${ }^{2}$ do tipo de unidade de produção considerada, medido pela renda agrícola (RA).

$\mathrm{O}$ valor agregado corresponde ao fluxo de riqueza anual produzido por meio do sistema de produção. Ele é calculado por, VA = PB - CI - D, onde:

$\mathrm{PB}=$ soma da produção física multiplicada pelos seus respectivos preços de venda (produções comerciais) ou de compra no mercado mais acessível (produção de subsistência);

CI = soma do consumo intermediário obtido pela multiplicação das quantidades físicas dos insumos pelos seus preços compra;

$\mathrm{D}$ = soma da depreciação das máquinas, equipamentos e benfeitorias.

A renda agrícola corresponde à diferença entre o valor agregado obtido por meio do sistema de produção e a soma da remuneração dos diferentes agentes sociais que participam direta ou indiretamente da produção, ou seja, RA = VA $-\mathrm{S}-\mathrm{J}-\mathrm{T}-\mathrm{I}$, onde:

$\mathrm{VA}=$ valor agregado

$\mathrm{S}$ = salários (pagos aos trabalhadores contratados)

$\mathrm{J}=$ juros (pagos a Bancos ou outras instituições financeiras)

$\mathrm{T}=$ arrendamentos (pagos ao proprietário da terra)

I = impostos (pagos ao Estado)

A partir do cálculo da RA produzida pelo sistema de produção foi elaborado um modelo linear que descreve a variação do resultado econômico global do sistema de produção em relação à superfície agrícola útil (SAU) explorada por unidade de trabalho familiar (UTF) empregada no processo produtivo da unidade de produção em estudo.

Para análise da remuneração do trabalho familiar (RW) construiu-se gráfico cuja ordenada são os valores da renda agrícola por unidade de trabalho familiar (RA/UTF) e a abscissa corresponde à superfície agrícola útil por unidade de trabalho familiar (SAU/UTF), conforme expressa a equação a seguir:

$\mathrm{RW}=(\mathrm{PB}-\mathrm{GP}) / \mathrm{SAU} * \mathrm{SAU} / \mathrm{UTF}-\mathrm{GNP} / \mathrm{UTF}$

Temos assim uma fórmula de reta do tipo: $\mathrm{y}=\mathrm{a} * \mathrm{x}-\mathrm{b}$, onde:

$\mathrm{y}=$ é a variável dependente e representa a RW, ou seja, RA/UTF;

$\mathrm{a}=$ é o coeficiente angular e determinam a inclinação da reta, representada pela produção

\footnotetext{
${ }^{2} \mathrm{O}$ indicador básico é constituído pelo nível de reprodução social (NRS), que representa a renda mínima necessária para reproduzir os meios de produção da unidade e remunerar o trabalho familiar ao longo dos anos, permitindo boa qualidade de alimentação, habitação, vestuário, saúde, lazer e educação. O parâmetro utilizado é o custo de oportunidade do trabalho (comparado com a renda de outras fontes potenciais), medido, neste estudo, através de um salário mínimo mensal $(R \$ 700,00)$ por unidade de trabalho familiar, incluído o 13 o salário. LIMA et al. (2005).
} 
bruta menos os gastos proporcionais ${ }^{3}$ à superfície (PB - GP)/SAU;

$\mathrm{x}$ = é a variável independente e representa a área destinada por UTF (SAU/UTF);

$\mathrm{b}=$ é o coeficiente linear, o ponto em que a reta atinge o eixo do y (ordenada), representa os gastos não proporcionais ${ }^{4}$ (GNP/UTF).

Economicamente, o coeficiente angular "a", isto é (PB-GP)/SAU, corresponde à contribuição em relação à área útil do sistema de produção, a qual indica a intensidade com que é utilizada a área. Quanto maior for a produção bruta e menores forem os gastos proporcionais por unidade de área, mais vertical será a reta. E, quanto maior o capital fixo por pessoa necessário para implantar o sistema de produção (o coeficiente linear "b") e menor a contribuição em relação à área (o coeficiente angular "a"), maior será a superfície agrícola útil por pessoa para que cada trabalhador da família possa receber uma renda suficiente para a sua manutenção na atividade agrícola ao longo do tempo (SILVA NETO \& BASSO, 2005).

\section{RESULTADOS E DISCUSSÃO}

\section{CARACTERIZAÇÃO DA UNIDADE DE PRODUÇÃO AGRÍCOLA}

A UPA de estudo se situa na localidade de Nhu-Porã, município de São Borja/RS/Brasil, a qual pertence a categoria social do tipo familiar ${ }^{5}$, possuindo três (3) unidades de trabalho familiar (UTF) como força de trabalho disponível para o desenvolvimento das atividades produtivas. A força de tração é do tipo semi-mecanizada, sendo que o aparelho de produção para viabilizar as atividades é composto basicamente por instalações e benfeitorias em bom estado de conservação, como galpão de madeira, estábulo misto e cercas de arame liso. Quanto às máquinas e equipamentos à disposição na unidade de produção, consta de trator médio, grade niveladora, semeadeira, pé-de-pato, reboque/carretão, pulverizador de barra, ensiladeira, triturador elétrico, ordenhadeira, resfriador de leite a granel, pulverizador costal, aparelho de cerca elétrica, entre outras ferramentas manuais.

\footnotetext{
${ }_{3}^{3}$ Gastos proporcionais são custos de produção que são proporcionais à área cultivada ou ao tamanho do rebanho (óleo diesel, horas-máquina, sementes, adubos, agrotóxicos, mão-de-obra, gastos com a colheita - mão-de-obra ou máquina - alimentação dos animais, contribuição social (CESSR), juros de custeio).

${ }^{4}$ Gastos não proporcionais são aqueles custos que não dependem (ou dependem de forma insignificante) da área cultivada ou do tamanho do rebanho, tais como: a depreciação da maior parte das instalações (curral, estábulo, cercas externas), das máquinas e equipamentos (tratores, implementos agrícolas, motores), pagamento de impostos e taxas fixas (ITR, Sindicato), juros de investimento, salários permanentes e arrendamento de terras.

${ }^{5} \mathrm{~A}$ unidade de produção familiar caracteriza-se pela gestão dos recursos e o processo de trabalho ser realizado pelo proprietário, que participa diretamente no processo produtivo com sua família, contudo, pode-se eventualmente ser contratada mão-de-obra para conduzir o sistema de produção.
} 
A propriedade possui uma estrutura fundiária de exploração de 22 hectares de área aproveitável própria onde desenvolve produção em escala comercial de leite e soja, aliada a uma produção para subsistência da família.

Em relação aos aspectos técnicos, na produção de leite o rebanho é composto predominantemente pela raça holandesa, possuindo um plantel médio de 15 vacas em lactação, produzindo um total de 224 litros diariamente, com uma produtividade média de 14 litros/vaca/dia. Nesta unidade de produção, o ciclo produtivo se baseia na reprodução através de inseminação artificial, adotando as fases de cria e recria de novilhas para reposição das matrizes descartadas, sendo os machos recém-nascidos descartados para venda. O manejo alimentar dos animais é através de pastoreio direto em potreiro de grama nativa e pastagens anuais (milheto, sorgo forrageiro, azevém e aveia preta) e perenes (tifton 85, brachiaria), além de complementação com silagem de milho de planta inteira ou grão úmido. Há uma suplementação com sal mineral e, também, é fornecida uma complementação de concentrado com farelo de soja, trigo e milho triturado. No manejo sanitário, além das vacinas obrigatórias, são realizados testes e prevenção de mastite e controle de endo e ecto parasitas.

Em relação à produção de soja, está é desenvolvida em 6 hectares, tendo um produtividade de 36 sacas/ha. Num segundo plano, são desenvolvidos diversos produtos para autoconsumo e segurança alimentar da família.

\section{ANÁLISE DA SITUAÇÃO SOCIOECONÔMICA DA UNIDADE DE PRODUÇÃO AGRÍCOLA}

Do ponto de vista do desempenho econômico do sistema de produção pode-se afirmar que globalmente os resultados da UPA são compensadores, embora possam ser melhorados. De acordo com o quadro 1, observa-se que o valor da Produção Bruta (PB) anual chega a

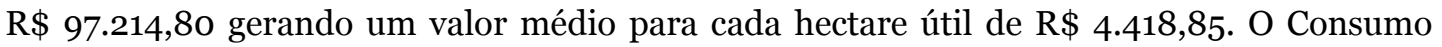
Intermediário (CI), ou seja, o valor dos insumos e dos serviços comprados e consumidos ao longo do ano perfaz um valor de $\mathrm{R} \$ 35.004,25$ consumindo $36 \%$ em relação ao valor bruto da

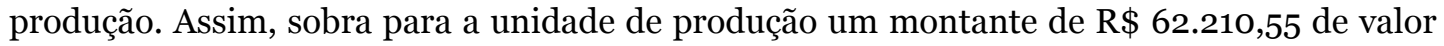
agregado bruto (VAB) tendo um valor médio por hectare útil de $\mathrm{R} \$ 2.827,75$. Neste sentido, o percentual calculado de $64 \%$ de VAB indica um nível de eficiência bom.

Quadro 1: Síntese dos resultados econômicos do sistema de produção.

\begin{tabular}{|c|c|c|c|c|c|c|c|c|c|c|}
\hline \multicolumn{10}{|c|}{ QUADRO SÍNTESE DOS RESULTADOS ECONÔMICOS POR SUBSISTEMAS } \\
\hline Atividades & Área (Ha) & P.B. & C.I. & V.A.B. & Dep. & V.A.L. & D.V.A. & R.A. & VAB/Ha & VAL/Ha \\
\hline Bov. Leite & 15,00 & $74.800,00$ & $28.592,03$ & $46.207,97$ & $8.290,50$ & $37.917,48$ & $2.482,14$ & $35.435,34$ & $3.080,53$ & $2.527,83$ \\
\hline Soja & 6,00 & $15.120,00$ & $4.692,78$ & $10.427,22$ & 840,18 & $9.587,03$ & 955,34 & $8.631,70$ & $1.737,87$ & $1.597,84$ \\
\hline Autoconsumo & 1,00 & $7.294,80$ & $1.719,43$ & $5.575,37$ & 405,36 & $5.170,01$ & 74,29 & $5.095,72$ & $5.575,37$ & $5.170,01$ \\
\hline TOTAL & 22,00 & $97.214,80$ & $35.004,25$ & $62.210,55$ & $9.536,03$ & $52.674,52$ & $3.511,76$ & $49.162,76$ & $10.393,77$ & $9.295,68$ \\
\hline
\end{tabular}


Ainda analisando o quadro 1, a depreciação das instalações e benfeitorias, das máquinas e equipamentos soma $\mathbf{R} \$$ 9.536,03 ao ano, correspondendo a um cálculo de 9,8\% em relação ao valor da Produção Bruta. Assim o valor agregado líquido (VAL), que representa a riqueza gerada pela unidade de produção ao ano, foi de $\mathrm{R} \$ 52.674,52$ e por área útil foi de $\mathrm{R}$ \$ 2.394,30 cujo percentual reduziu para 54,18\%. Os gastos com impostos e juros que integrou a distribuição do valor agregado (DVA) foram de $\mathrm{R} \$ 3.511,76$ e com isso sobrou de renda agrícola (RA) um montante de $\mathrm{R} \$ 49.162,76$. Em percentual a renda agrícola que ficou para a família-unidade de produção foi de 50,57\% da PB.

Quanto ao comportamento econômico das atividades, verifica-se que a atividade leiteira, com um rendimento físico considerado normal de 14 l/vaca/dia, apresenta um VAB/Ha de $\mathrm{R} \$ 3.080,53$. Este valor pode ser considerado bom, possivelmente devido ao baixo custo com insumos utilizados na atividade, no entanto, pode ser melhorado a partir de uma maior intensificação da atividade produtiva. A produção de soja, presente nessa unidade de produção, apresenta $\mathrm{R} \$ 1.737,87$ de $\mathrm{VAB} / \mathrm{ha}$, sendo considerado de baixa intensidade no sistema de cultivo. Em contrapartida, a produção para o autoconsumo familiar apresenta significativa importância e intensidade produtiva para abastecer a família.

O resultado da modelagem econômica global do sistema de produção adotado na UPA encontra-se resumidos na figura 1 e no quadro 2, permitindo avaliar a dimensão da situação socioeconômica em relação ao nível de reprodução social, bem como analisar o potencial (intensificação) de cada subsistema de produção na composição da renda agrícola.

Como se pode observar na inclinação da reta da figura (coeficiente "a"), a atividade leiteira quando considerada do ponto de vista da contribuição da renda agrícola por unidade de área tem uma significativa contribuição, equivalente de $\mathrm{R} \$ 2.965,84$ utilizando 5,o SAU/UTF. Esse valor elevado pode ser explicado pelos bons rendimentos em termos de produtividade por animal associado a uma escala de produção que proporciona um volume entregue relativamente alto, elevando assim, o preço recebido pelo litro do leite, bem como também fruto dessa contribuição, a venda de vacas de descarte e novilhos. Também é de se considerar os gastos em insumos serem relativamente baixo.

O subsistema de produção de soja apresenta-se com baixa intensidade, como se observa na inclinação da reta (coeficiente “a”), fruto de uma baixa produtividade por superfície utilizada, assim como baixa escala de produção do sistema de cultivo adotado. Assim, sua produção contribui na renda agrícola por unidade de superfície equivalente ao valor de $\mathrm{R} \$ 1.604,31$.

Já o subsistema para o autoconsumo familiar, produz uma diversificada quantidade de produtos para alimentação da família, apresentando considerável nível de contribuição econômica, como mostra a inclinação da reta (coeficiente "a"), equivalente ao valor de $\mathrm{R} \$$ 5.575,37 de renda agrícola em relação à superfície agrícola útil. 


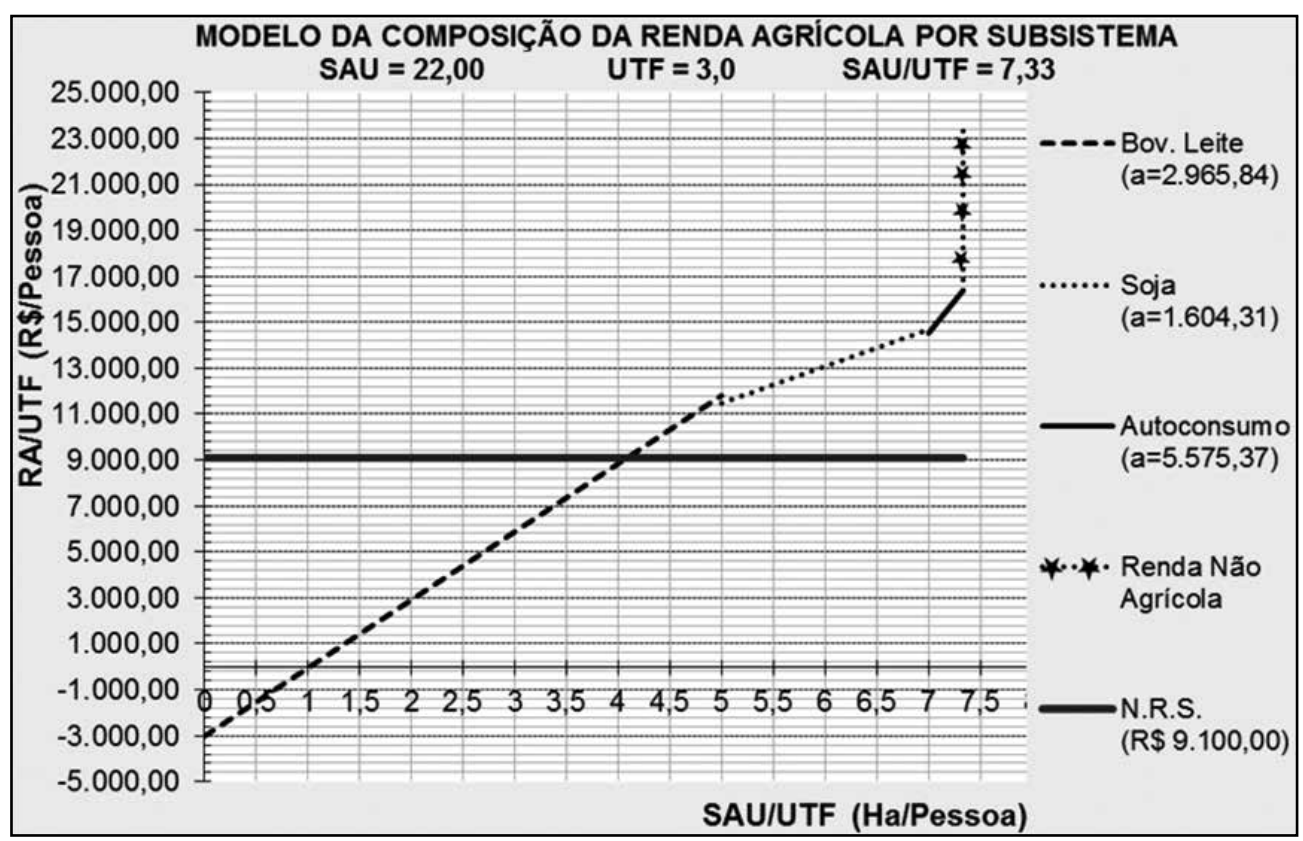

Figura 1: Modelo da composição da renda agrícola do sistema de produção Leite / Soja / Autoconsumo / RNA. Fonte: Dados da pesquisa, 2014.

Já os dados do quadro 2 apontam a produção de leite como principal fonte de renda para a unidade de produção familiar, contribuindo aproximadamente com $74 \%$ na renda agrícola, no entanto, explorando a maior parte do sistema de produção, ocupando uma área útil em torno de $68 \%$. Já a produção de soja contribui ao redor de $16 \%$ na renda agrícola, utilizando em torno de $27 \%$ de superfície agrícola útil. Já a produção de hortifrutigranjeiros para o autoconsumo da família contribui significativamente com o equivalente a pouco mais de $9 \%$ de renda no resultado econômico com uma área útil de exploração ao redor de $5 \%$ do sistema de produção.

Quadro 2: Composição da renda agrícola do sistema de produção Leite/Soja/Autoconsumo/RNA.

\begin{tabular}{|c|c|c|c|c|c|c|c|c|}
\hline \multicolumn{9}{|c|}{ MODELO DA COMPOSIÇÃO DA RENDA AGRÍCOLA POR SUBSISTEMAS } \\
\hline & Coeficiente "a" & \multicolumn{2}{|c|}{ Coeficiente "x" } & \multicolumn{2}{|c|}{ Coeficiente "b" } & \multicolumn{2}{|c|}{ Contribuição da R.A. } & \\
\hline \multicolumn{9}{|c|}{ 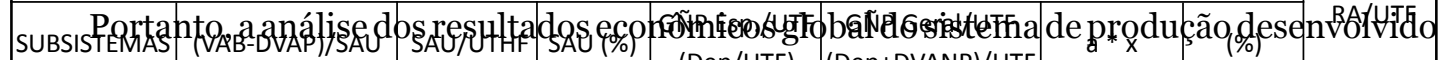 } \\
\hline Soja & $1.604,31$ & 2,00 & 27,27 & 0,00 & 331,39 & $3.208,62$ & 16,13 & $2.877,23$ \\
\hline Autoconsumo & $5.575,37$ & 0,33 & 4,55 & 0,00 & 159,88 & $1.858,46$ & 9,34 & $1.698,57$ \\
\hline TOTAL & $10.145,51$ & 7,33 & 100,00 & $1.378,01$ & $2.130,67$ & $19.896,26$ & 100,00 & $16.387,59$ \\
\hline$y=a^{*} x-b$ & & 37,59 & & Rend & a Não Agrícola & Ñ.A.) & $7.020,00$ & \\
\hline
\end{tabular}

Fonte: Dados da Pesquisa, 2014. 
UTF), resultando num valor de R \$ 16.387,59 de renda agrícola para cada unidade de trabalho familiar, portanto, um valor superior ao nível de reprodução social (NRS), estabelecido em R \$ 9.100,0o por UTF ao ano. Com esse desempenho, pode-se dizer que, em condições favoráveis, está garantida a reprodução socioeconômica da família-unidade de produção no médio e longo prazo. Contudo, a renda não agrícola (RNA) oriunda de aposentadoria do Instituto Nacional de Seguridade Social (INSS) de R $\$$ 7.020,oo obtida por um membro da família, contribui significativamente para elevar a renda global familiar.

\section{CONSIDERAÇÕES FINAIS}

Ao concluir este diagnóstico técnico e socioeconômico, tendo como objeto de estudo uma UPA familiar, pode-se afirmar que o mesmo se constitui como um importante referencial para a gestão estratégica dos negócios agrícolas, bem como na tomada de decisões e planejamento da organização da produção agrícola.

A unidade de produção objeto de estudo apresenta uma estrutura satisfatória para realização das atividades produtivas, cujas benfeitorias, máquinas e equipamentos são adequados e suficientes para suprir as necessidades.

Verifica-se uma significativa circulação de capital na propriedade analisada. Isso se deve em grande parte a atividade leiteira que contribui com um fluxo mensal de dinheiro, o que torna esta atividade muito interessante, já que se tem um fluxo de caixa com uma entrada mensal considerável de dinheiro na unidade de produção. Portanto, a escolha da atividade leiteira está coerente, pois se adéqua muito bem as condições estruturais e de funcionamento da UPA, apresentando bom potencial de valor agregado por hectare, além de ter boas perspectivas de mercado.

De acordo com o aconselhamento técnico e gerencial, dentre as proposições possíveis, recomenda-se a intensificação da atividade leiteira, em detrimento da cultura da soja, que apresenta menor potencial de valor agregado além de maior exposição aos riscos climáticos como é caso das estiagens. 


\section{REFERÊNCIAS BIBLIOGRÁFICAS}

Andrade, José Geraldo de (1985). “Administração rural: um novo enfoque ao seu ensino”. in: Congresso Brasileiro de Economia e Sociologia Rural. Anais. São Paulo: Sober, v. 1.

(2001). "Introdução à administração rural”. Lavras: Editora da Universidade Federal de Lavras.

Basso, David; Delgado, Nelson Giordano; Silva Neto, Benedito (2003). "O Estudo de Trajetórias de Desenvolvimento Rural”. Desenvolvimento em Questão, Ijuí: Editora Universidade Regional do Noroeste do Estado do Rio Grande do Sul, n. 1, p. 73-105.

Brossier, J. et al (1990). "Modélisation systémique el systéme agraire: decision et organization”. Paris: Inra.

Dufumier, Marc (2007). "Projetos de desenvolvimento agrícola: manual para especialistas". Salvador: Editora da Universidade Federal da Bahia.

Hoffmann, Rodolfo et al (1987). “Administração da Empresa Agrícola”. 5 a Ed. São Paulo: Pioneira.

Lima, Arlindo Jesus Prestes de et al (2005). Administração da unidade de produção familiar: modalidade de trabalho com agricultores. Ijuí: Editora da Universidade Regional do Noroeste do Estado do Rio Grande do Sul - Unijuí.

Mazoyer, Marcel \& Roudart, Laurence (2001). "História das Agriculturas do Mundo, do Neolítico à Crise Contemporânea”. Lisboa: Instituto Piaget.

Megginson, L.C. (1998). “Administração: conceitos e aplicações”. 4. ed. São Paulo: Harbra, 614 p.

Miguel, Lovois de Andrade (2010). "Abordagem sistêmica da unidade de produção agrícola”. In: Wagner, Saionara Araújo et al . (Org). Gestão e planejamento de unidades de produção agrícola. Porto Alegre: Editora da Universidade Federal do Rio Grande do Sul.

Souza, R. de et al (1989). “Administração da fazenda”. 2. ed. Rio de janeiro: Globo, 211 p. 


\section{CURRÍCULUM VITAE}

\section{Adilson R. Paz Stamberg}

Doutorando em Administração pela Universidad Nacional de Missiones (UNaM), Argentina. Mestre em Desenvolvimento, Gestão e Cidadania pela Universidade Regional do Noroeste do Estado do Rio Grande do Sul (UNIJUÍ). Especialista em Gestão Agroindustrial pela Universidade Federal de Lavras (UFLA). Licenciado em Administração Rural pela Universidade Federal de Santa Maria (UFSM) e Bacharel em Administração pela Universidade Norte do Paraná (UNOPAR). Atualmente é Professor de Administração na Educação Básica, Técnica e Tecnológica e Diretor de Pesquisa, Extensão e Produção do Instituto Federal Farroupilha - Câmpus São Borja. adilson.stamberg@iffarroupilha.edu.br 